\title{
Effects of water and fertilizer managements on content and distribution of phosphorus in different parts of rice plants
}

\author{
G.B. Pang \& Z.H. Xu \\ School of Resources and Environment, University of Jinan, China
}

\begin{abstract}
KEYWORD: water and fertilizer managements; controlled irrigation; site-specific nutrient management; rice; phosphorus content; phosphorus accumulation; distribution

ABSTRACT: Based on the data from field experiments, the phosphorus content and phosphorus accumulation of rice plants were analyzed, and phosphorus distributions in different parts of rice were studied as well. The results showed that compared with farmers' fertilization practice (FFP), site-specific nutrient management (SSNM) increased the phosphorus content of leaf under controlled irrigation, and the phosphorus accumulation of leaf was high in the end. At the same time, the phosphorus content of stem \& sheath and roots were enhanced at jointing and booting stage, and the phosphorus accumulation of stem $\&$ sheath was increased as well. Also phosphorus content of panicle was higher than FFP at milk maturity stage. Compared with flooding irrigation, controlled irrigation reduced the phosphorus content of leaf and stem \& sheath. However, the phosphorus content of roots were improved with SSNM at jointing and booting stage, and the phosphorus accumulation under controlled irrigation condition recuperated at milk maturity stage. The phosphorus accumulation of panicle was higher under water saving irrigation condition. Water and fertilizer managements promote phosphorus transferring under controlled irrigation and SSNM condition, and the phosphorus efficiency was improved as well.
\end{abstract}

\section{INTRODUCTION}

Phosphorus (P) is an essential nutrient for crop growth and development. Rapid growth and early maturity, when soil $\mathrm{P}$ supply sufficiently, otherwise, the growth process is slow ${ }^{[1]}$. It believes that the effectiveness of phosphorus in soil is closely related to soil moisture. In the Traditional rice planting, soil under flooded conditions, $\mathrm{P}$ has the higher effectiveness level. With the popularity and applications of water saving irrigation technology, the growth period of paddy field under dry-wet alternate condition in most of the time, it increased soil redox potential and reduced the effectiveness of $\mathrm{P}$, finally restricted the ability of rice absorb phosphorus. Rice is more sensitive to $\mathrm{P}$ deficiency, $\mathrm{P}$ deficiency will restrain growth of rice plants growth, and content of $\mathrm{P}$ is the important factors that affect polished rice rate in rice ${ }^{[2]}$. Fageria pointed out the importance of rice requires adequate supply in the whole stages of phosphorus ${ }^{[3]}$. Lv Guoan consider water stress is bad for the rice to absorption of $\mathrm{P}$, more attentions should be paid to the phosphorus nutrient status of rice plants where water -saving irrigation is applied ${ }^{[4,5]}$. Zhou Chunling and Shen Qirong ${ }^{[6]}$ studied the phosphorus uptake difference between paddy rice and upland rice under different $\mathrm{P}$ level, Water stress retards the rice growth under low $\mathrm{P}$, but the effect of phosphorus in upland rice are more than paddy rice, application of phosphate fertilizer are more meaningful. Cui Yuanlai ${ }^{[2]}$ studied the upland rice phosphorus under different water conditions, that the yield slightly decreased when the soil water potential is $-30 \mathrm{kPa}$, but water productivity and phosphorus efficiency increased. Previous studies focused on single factor effect of water and fertilizer, there is less research on effects of water and fertilizer combined regulation. This paper set up two factors of irrigation and fertilization, through the experiment of different parts of rice phosphorus content and accumulation in the discussion and analysis, in order to provide basis for the selection of water and fertilizer management practices in rice production. 


\section{MATERIALS AND METHODS}

Overview of the experimental area

Experimental area located in Kunshan, Hohai University, State Key Laboratory Experimental Research Base $\left(31^{\circ} 15^{\prime} 15^{\prime \prime} \mathrm{N}, 120^{\circ} 57^{\prime} 43^{\prime \prime} \mathrm{E}\right)$, as the water area of Tai lake watershed, belongs to southern subtropical monsoon climate, the annual average temperature $15.5^{\circ} \mathrm{C}$, annual rainfall $1097.1 \mathrm{~mm}$, annual evaporation $1365.9 \mathrm{~mm}$, sunshine hours $2085.9 \mathrm{~h}$, annual average relative humidity $83 \%$, the average frost-free period 234 days. Local custom wheat rotation, soil is water-logged paddy yellow soil, tilth soil is heavy loam, bulk density $1.30 \mathrm{~g} / \mathrm{cm}^{3}, \mathrm{pH}$ value of 7.4 , soil organic carbon $30.3 \mathrm{~g} / \mathrm{kg}$, total nitrogen $1.79 \mathrm{~g} / \mathrm{kg}$, total phosphorus $1.4 \mathrm{~g} / \mathrm{kg}$, total potassium $20.86 \mathrm{~g} / \mathrm{kg}$.

Design of Experiments

The experiments use split plot design. The main treatment are two ways of irrigation: Traditional Irrigation, marked by $\mathrm{T}$; Controlled Irrigation, marked by $\mathrm{C}$. The auxiliary treatment are two ways of fertilization: site-specific nutrient management, marked by SSNM ; farmers' fertilization practice, marked by FFP. Four treatments are $\mathrm{T}+\mathrm{S}(\mathrm{T}$ and $\mathrm{SSNM}), \mathrm{T}+\mathrm{F}(\mathrm{T}$ and FFP $), \mathrm{C}+\mathrm{S}(\mathrm{C}$ and SSNM) and $\mathrm{C}+\mathrm{F}(\mathrm{C}$ and FFP $)$, and every treatment is repeated 3 times, so there are 12 parts in all. The experimental rice variety is early-maturing in autumn 9998-3, which is transplanted at Jun 27th, and harvest at Oct 27th. Its growth period were 122 days.

Controlled Irrigation, except for keeping the surface of field a $5 \sim 25 \mathrm{~mm}$ shallow aquifer during green period and natural drying at yellow ripening stage, doesn't build any aquifers after irrigation in other growth period. Regarding soil moisture in root zone as control index and Irrigation upper limit as the saturated water content, the soil moisture lower at each growth period is $70 \%, 65 \%$, $60 \%, 70 \%, 75 \%, 80 \%$ and $70 \%$ of the saturated water content. Rice irrigation traditional mode, except for Field drying at the late tillering stage and natural drying at yellow ripening stage, builds 3$5 \mathrm{~cm}$ aquifers at other stages.

Regarding SPAD ( Soil and Plant Analyzer Development) as the control index, SSNM makes a real-time adjustment of crop fertilizer ${ }^{[7]}$, while FFP fertilizes according to local farmers' habit of fertilizing and amount. FFP applies fertilizer 2 days before the rice transplanting. On the 7 th day, 19th day and 43th day after transplanting, we apply tillering fertilizer, strong seedling fertilizer and panicle fertilizer, the fertilization rate (Converted into pure nitrogen) is 20.375, 51.975, 103.95 and $79.695 \mathrm{~kg} / \mathrm{hm}^{2}, 355.995 \mathrm{~kg} / \mathrm{hm} 2$ totally. SSNM applies one time strong seedling fertilizer less than FFP, the fertilization rate is $104.98,46.78$ and $71.73 \mathrm{~kg} / \mathrm{hm}^{2}, 223.49 \mathrm{~kg} / \mathrm{hm}^{2}$ totally.

Observation contents and methods

(1)Plant dry matter: Each processing chooses 2 typical plants during every growth periods, puts their roots, stems, leaves and panicles into $105^{\circ} \mathrm{C}$ oven to kill out for $30 \mathrm{~min}$, lowers the temperature to $70^{\circ} \mathrm{C}$ and makes the determination of dry matter weight after drying 48 hours.

(2)The total phosphorus content of plants: The dried samples are crushed and added through 40 mesh screen to prepare for the determination of nutrient element content. After using concentrated $\mathrm{H}_{2} \mathrm{SO}_{4}-\mathrm{H}_{2} \mathrm{O}_{2}$ to disinfect, the samples are determined by Mo-Sb colorimetry.

\section{RESULTS AND ANALYSIS}

\section{$P$ content and accumulation of rice leaves}

As shown in Figure 1, the trends of the rice leaves' phosphorus content of four treatments are similar. At the vegetative growth stage which is during the early growth period, the rice leaves' phosphorus content is about $3-5 \mathrm{mg} / \mathrm{g}$. When it reaches to the later reproductive growth stage, phosphorus of the leaves transfer to the grain, and the phosphorus content of leaves decreases. If the same way of irrigation is used, rice leaves' phosphorus content of FFP treatment is higher than that of SSNM treatment under traditional irrigation, while the controlled irrigation is on the opposite. High nitrogen level restricts the rice leaves' absorption and running of phosphorus under drought stress, and that is the same with the conclusion of Zhu Weiqin's study ${ }^{[8]}$. If the same way of fertilization is 
used, rice leaves' phosphorus content of FFP treatment under controlled irrigation is lower about $1 \mathrm{mg} / \mathrm{g}$ than that under traditional irrigation, while the differences of SSNM are little. The analysis shows that, under the condition of water saving irrigation, the applying of high nitrogen fertilizer prevent the rice leaves absorbing phosphorus.

The cumulative amount of phosphorus equals to the product of phosphorus content and biomass of different organs. As can be seen from Figure 2, $\mathrm{P}$ accumulation of rice leaf was ascend in first and descend at last, in the late of jointing and booting stage reaches maximum. At late tillering stage, $\mathrm{T}+\mathrm{F}$ was higher than that in $\mathrm{C}+\mathrm{F}, \mathrm{C}+\mathrm{S}, \mathrm{T}+\mathrm{S}$, about $15.3 \%, 20.0 \%, 13.6 \%$ respectively, and at late jointing and booting stage were higher with $22.7 \%, 10.2 \%, 5.1 \%$, respectively. From heading to flowering, The phosphorus accumulation of the processed rice leaf in $\mathrm{C}+\mathrm{F}$ were closed to that in $\mathrm{T}+\mathrm{F}$, and were significant higher than that in $\mathrm{C}+\mathrm{F}, \mathrm{T}+\mathrm{S}$ in the same moisture conditions. At milkystage, while the Aging of plants and transferring phosphorus to grain, the leaf phosphorus accumulation has dropped, and in $\mathrm{C}+\mathrm{S} 13.8 \%$ above head sprouting. From the whole growth period, fertilization modes under water regulation has obvious implications for the phosphorus accumulation of rice leaf at head sprouting. Moderate water deficit postpone the senescence and extend the time of photosynthetic of leaf under the condition of SSNM, which can provide more phosphorus assimilate of rice leaves until the late growth stage.

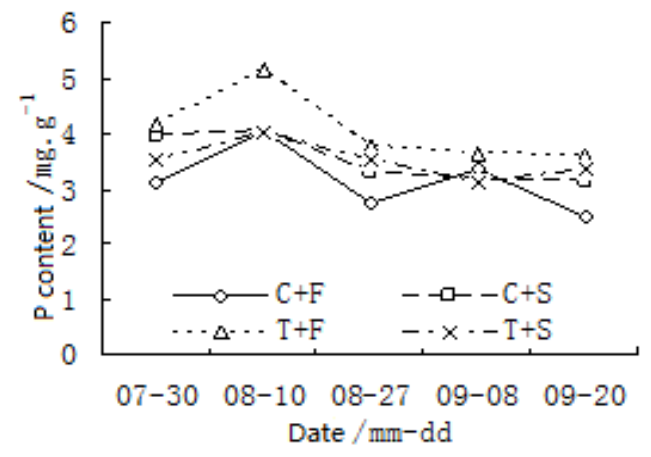

Figure 1. P content of rice leaves

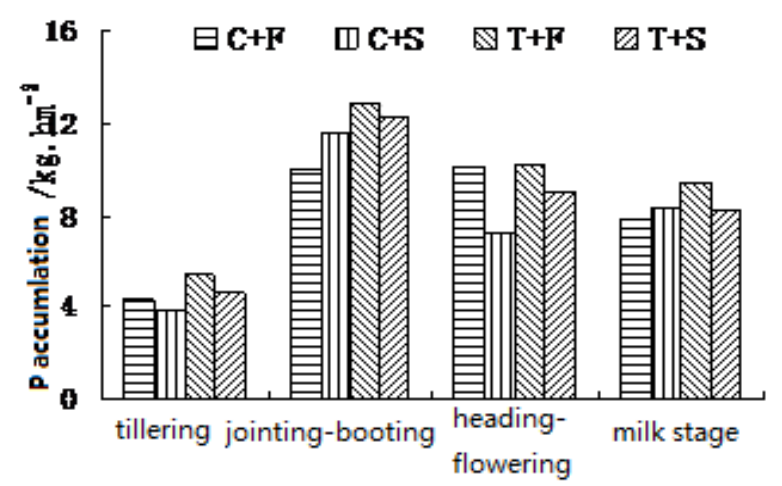

Figure 2. $\mathrm{P}$ accumulation of rice leaves

\section{$P$ content and accumulation of rice stem}

As shown in Figure 3, the change of the rice stems' phosphorus content is similar with that of leaves during the whole growth period. The rice stems' phosphorus content is at a rather high level during the early growth period, and it reaches to about $4-6 \mathrm{mg} / \mathrm{g}$. After entering the reproductive growth stage, the content decreases to about $3-5 \mathrm{mg} / \mathrm{g}$. If the same way of irrigation is used, rice stems' phosphorus content of SSNM is higher than that of FFP at the later booting stage and the heading blossom stage. The applying of nitrogen fertilizer at the early stage inhibits absorbing phosphorus from the rice stems at the reproductive growth stage. If the same way of fertilization is used, rice stems' phosphorus content under traditional irrigation is higher than that under the controlled irrigation, because the soil aeration is in good condition under controlled irrigation and the change of oxidation reduction potential affects the effectiveness of phosphorus. The analysis shows that, rice stems' phosphorus content in $\mathrm{C}+\mathrm{S}$ doesn't obviously decrease, and the applying of appropriate 
amount of nitrogen fertilizer is helpful for the absorbing of the rice stems' phosphorus under controlled irrigation.

As can be seen from Figure 4, The phosphorus accumulation of stem and sheath of rice showed a rise first and decreased subsequently. Phosphorus accumulation of the rice stem and sheath was higher at tillering stage and milk stage in $\mathrm{C}+\mathrm{T}$ and $\mathrm{T}+\mathrm{F}$ than in $\mathrm{C}+\mathrm{S}$ and $\mathrm{T}+\mathrm{S}$, and it has no different in the same fertilizer level. At tillering stage, SSNM were higher than FFP in jointing-booting stage. Phosphorus accumulation of rice stem and sheath in $\mathrm{T}+\mathrm{S}$ at heading to flowering period was significantly higher than $\mathrm{C}+\mathrm{F}, \mathrm{C}+\mathrm{S}, \mathrm{T}+\mathrm{F}$ treatments with $32.6 \%, 44.6 \%, 53.5 \%$. $\mathrm{C}+\mathrm{S}$ and $\mathrm{T}+\mathrm{F}$ had a peak value at jointing-booting stage, and $\mathrm{C}+\mathrm{F}$ and $\mathrm{T}+\mathrm{S}$ had the peak at heading to flowering. Under Water Stress, stem-sheath's phosphorus accumulation was limited by high nitrogen level, and it was significantly affected by fertilization modes at tillering and milk stage.

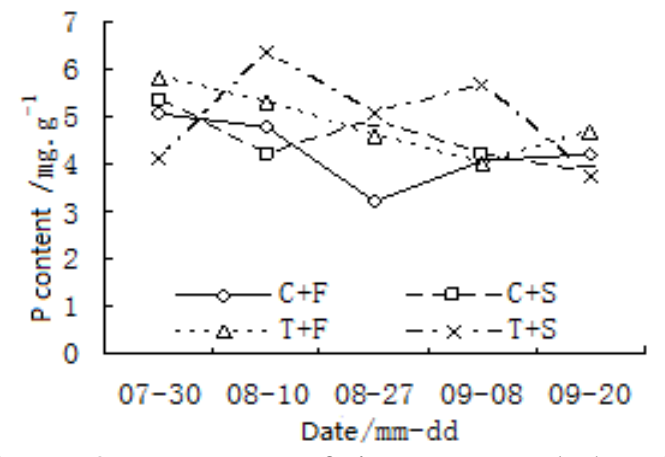

Figure 3. P content of rice stem and sheath

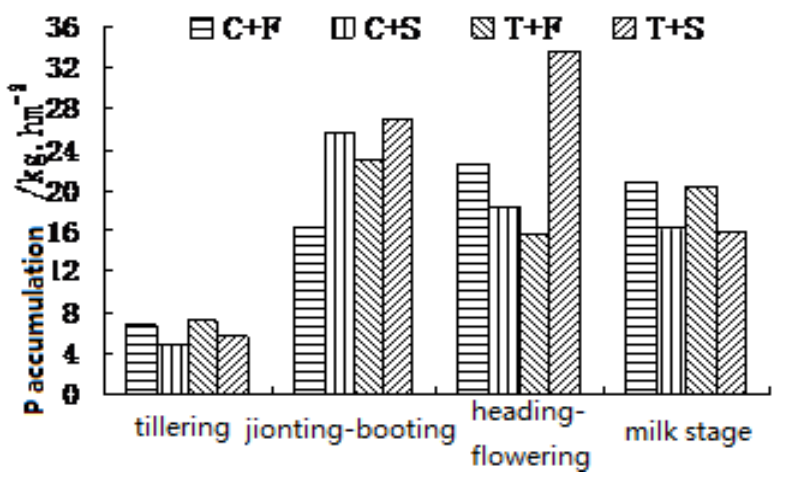

Figure 4. $\mathrm{P}$ accumulation of rice stem and sheath

\section{$P$ content and accumulation of rice roots}

As shown in Figure 5, the phosphorus content of rice roots appear the "W" variation trend. During the early growth period, the trend of all treatments are basically the same. But at the milk stage, different fertilizer treatments perform rather differently, FFP has recovered slightly while SSNM decreases slowly. If the same way of irrigation is used, at the vegetative growth stage, the rice roots' phosphorus content of FFP is higher than SSNM. Among them, C+F treatment is higher the other treatments and the applying of nitrogen fertilizer makes up for the effect of water deficit at ascertain extent. If the same way of fertilization is used, at the early reproductive growth stage (Aug 27th), the rice roots' phosphorus content of FFP under controlled irrigation is lower than that under traditional irrigation. On the opposite, at the later reproductive growth stage(Sep 8h \& Sep 20th ), the rice roots' phosphorus content of SSNM under controlled irrigation is obviously lower than that under traditional irrigation. The analysis shows that, the water saving irrigation will reduce the rice roots' phosphorus content, but the appropriate fertilization is helpful for rice roots' phosphorus uptake under water regulation.

As shown in Figure 6, the phosphorus accumulation of rice roots under different water and fertilizer controls firstly increased then decreased, and it is synchronized to the accumulation amount of root dry matter. At the tillering stage and booting stage, the phosphorus accumulation of rice roots in $\mathrm{C}+\mathrm{S}$ and $\mathrm{T}+\mathrm{S}$ were higher than that in $\mathrm{C}+\mathrm{F}$ and $\mathrm{T}+\mathrm{F}$. At heading blossom stage, the phosphorus ac- 
cumulation of rice roots in $\mathrm{T}+\mathrm{F}$ and $\mathrm{T}+\mathrm{S}$ were significant higher than that in $\mathrm{C}+\mathrm{F}$ and $\mathrm{C}+\mathrm{S}$ about $33.6 \%$ and $64 \%$. The root senescence at the milk stage leads to the decreasing of the phosphorus accumulation of rice roots, while $\mathrm{C}+\mathrm{F}$ and $\mathrm{C}+\mathrm{S}$ show the opposite trend. Because controlled irrigation delayed the root senescence and made it keep quite strong uptake ability. It can be seen from the analysis, at the vegetative growth stage, SSNM is helpful for the phosphorus accumulation of rice root under water deficit, and the phosphorus accumulation will rebound to a rather high level at the later stage.

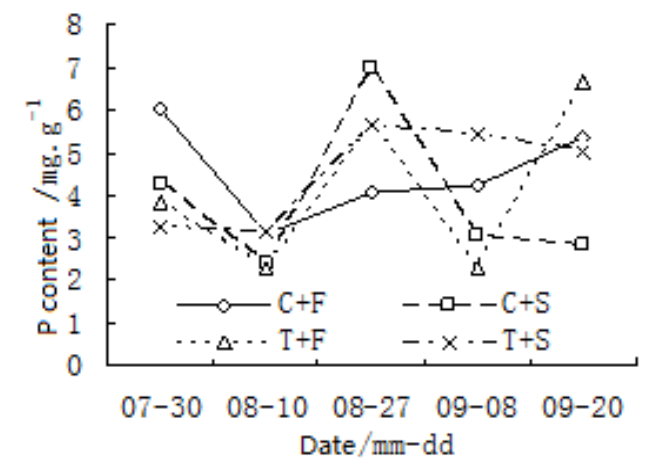

Figure 5. $\mathrm{P}$ content of rice roots

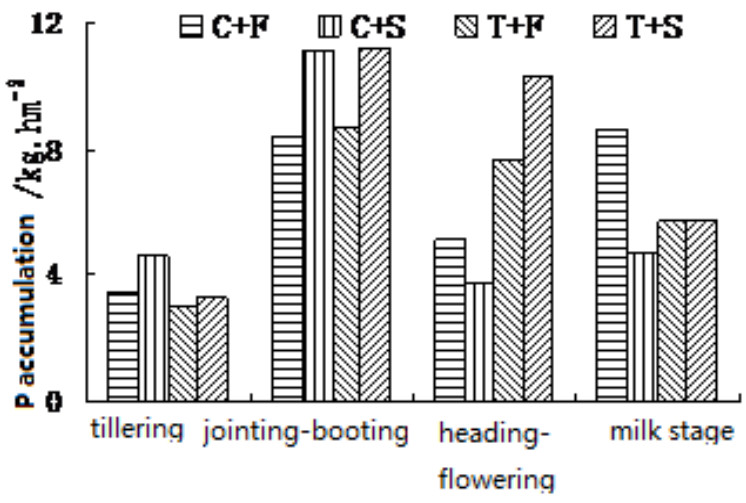

Figure 6. P accumulation of rice roots

\section{$P$ content and accumulation of rice panicle}

As shown in Figure 7, at the later stage of elongation and booting, the rice panicles' phosphorus content is relatively high between 3.5 to $4.5 \mathrm{mg} / \mathrm{g}$, and then presents downtrend. If the same way of fertilization is used, at the heading blossom stage(Sep 8th), the rice panicles' phosphorus contents of $\mathrm{C}+\mathrm{F}$ and $\mathrm{C}+\mathrm{S}$ are more or less similar, obviously higher than that of $\mathrm{T}+\mathrm{F}$ and $\mathrm{T}+\mathrm{S}$. Under the same irrigation mode, the rice grains' phosphorus content of SSNM is higher than that of FFP, and at milk stage, rice panicles' phosphorus contents are higher than those of $\mathrm{C}+\mathrm{F}$ and $\mathrm{T}+\mathrm{F} 5.3 \%$ and $12.5 \%$. The analysis shows that at the heading blossom stage controlled irrigation increased the rice panicles' phosphorus content. Panicles' phosphorus content of SSNM at milk stage is higher than FFP, controlled irrigation and SSNM promoted the rice panicles' phosphorus.

As shown in Figure 8, at reproductive growth stage, the phosphorus of rice's vegetative organs transfers to panicles, so the phosphorus accumulation of panicles increase gradually. At the booting stage, the $\mathrm{C}+\mathrm{S}$ and $\mathrm{T}+\mathrm{S}$ were higher than $\mathrm{C}+\mathrm{F}$ and $\mathrm{T}+\mathrm{F}$ with $79.9 \%$ and $27.2 \%$, the phosphorus accumulation abilities of rice's panicles under SSNM is stronger than FFP, and the differences are obvious under controlled irrigation. At the heading blossom stage, $\mathrm{T}+\mathrm{S}$ is obviously higher than $\mathrm{C}+\mathrm{F}$, $\mathrm{C}+\mathrm{S}, \mathrm{T}+\mathrm{F}$, with $52.5 \%, 43 \%$ and $39.1 \%$, that is due to the high panicles biomass. At milk stage, the phosphorus accumulation of panicles under $\mathrm{C}+\mathrm{S} 、 \mathrm{~T}+\mathrm{S}$ is $15.3 \%$ and $29.6 \%$ higher than $\mathrm{C}+\mathrm{F}$ and $\mathrm{T}+\mathrm{F}$. The results show that, SSNM doesn't reduce rice panicles' phosphorus content, and the SSNM and control irrigation promote the transferring of the phosphorus to growth center. 


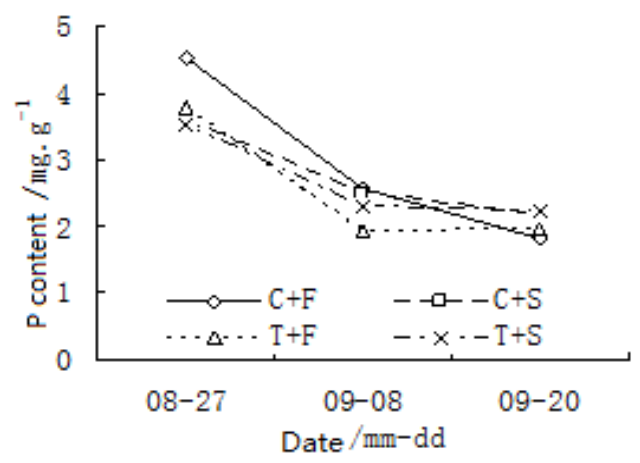

Figure 7. $\mathrm{P}$ content of rice panicle

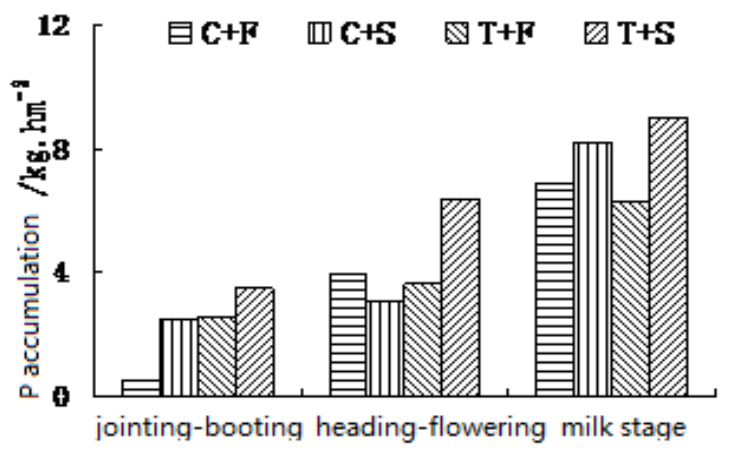

Figure 8. P accumulation of rice panicle

\section{Distribution of phosphorus in rice plants}

As known in Table 1, with the advance of growth stage, Plant growth center transfers, so phosphorus moves from vegetative organs to spikes to supply the formation and growth of rice's spikes. The amount of phosphorus in roots stems and leaves increasingly decreases, while that in spikes gradually increases. From the elongation and booting stage to the reproductive growth period of the milk stage, the amount of $\mathrm{C}+\mathrm{F}, \mathrm{C}+\mathrm{S}, \mathrm{T}+\mathrm{F}$ and $\mathrm{T}+\mathrm{S}$ increased by $17.82 \%, 19.34 \%, 14.11 \%$ and $17.82 \%$, among which $\mathrm{C}+\mathrm{S}$ is the largest increasing. At the heading blossom stage, the ratio of the panicle' phosphorus under different treatment is not obviously different, when it comes to the milk stage, $\mathrm{C}+\mathrm{S}$ and $\mathrm{T}+\mathrm{S}$ are obviously higher than $\mathrm{C}+\mathrm{F}$ and $\mathrm{T}+\mathrm{F}$, and which is more obvious under controlled irrigation. It shows that SSNM is helpful for phosphorus to transfer to growth center, controlled irrigation makes rice keeping many functional leaves at grain filling stage, and which is helpful for the accumulation of photosynthetic products and the grain filling, improving the utilization efficiency of phosphorus ${ }^{[9]}$. 
Table 1. Phosphorus distribution proportion of rice plant $/ \%$

\begin{tabular}{cccccc}
\hline Treatment & & $\mathrm{C}+\mathrm{F}$ & $\mathrm{C}+\mathrm{S}$ & $\mathrm{T}+\mathrm{F}$ & $\mathrm{T}+\mathrm{S}$ \\
\hline \multirow{3}{*}{ jointing-booting stage } & Root & 18.24 & 21.8 & 18.36 & 20.68 \\
& Stem & 49.71 & 50.16 & 48.65 & 50.11 \\
& Leaf & 30.34 & 22.66 & 27.15 & 22.64 \\
& panicle & 1.71 & 5.38 & 5.84 & 6.57 \\
& Root & 12.24 & 11.42 & 11.45 & 17.42 \\
heading-flowering stage & Stem & 54.12 & 57.05 & 46.88 & 56.54 \\
& Lraf & 24.27 & 22.17 & 30.71 & 15.21 \\
& panicle & 9.37 & 9.37 & 10.95 & 10.82 \\
& Root & 18.64 & 12.01 & 20.73 & 14.55 \\
& Stem & 44.97 & 41.83 & 40.56 & 40.12 \\
& Leaf & 16.86 & 21.45 & 18.75 & 20.94 \\
& panicle & 19.53 & 24.72 & 19.95 & 24.39 \\
\hline
\end{tabular}

\section{CONCLUSION AND DISCUSSION}

(1)With the advance of growth period, the phosphorus content of rice leaves, stems and panicle slowly decreased, while the phosphorus content of roots appear the "W" variation trend. Under controlled irrigation modes, compared with FFP, SSNM improved the phosphorus content of rice leaves, and increased stems and roots' phosphorus at the elongation and booting stage, as well as that of rice panicles at the milk stage. Under two different fertilization modes, compared with flooding irrigation, controlled irrigation decreased the phosphorus content of rice leaves and stems, while under SSNM, the rice roots phosphorus content of controlled irrigation at the elongation and booting stage was higher than that of flooding irrigation, and rice panicles phosphorus content of controlled irrigation was obviously higher than that of flooding irrigation at the heading blossom stage.

(2)The phosphorus accumulation of rice leaves, stems and roots rise first then fall. It reached to the maximum at the later stage of booting and the heading blossom stage, while the phosphorus accumulation of panicle is going on increasing. Under two different irrigation modes, compared with FFP, SSNM decreased the phosphorus accumulation of rice leaves both at the tillering stage, heading blossom stage, and milk stage, and that of stems and roots at the elongation and booting stage decreased as well, however the panicles' phosphorus increased. Under two different fertilization modes, compared with flooding irrigation, controlled irrigation decreased the phosphorus accumulation of rice leaves and roots, but increased rice stems' phosphorus under FFP at the heading blossom stage, meanwhile, panicles' phosphorus didn't obviously decrease at the milk stage.

(3)SSNM promote phosphorus to transfer to the growth center. Controlled irrigation makes rice keeping many functional leaves at grain filling stage, and that is helpful for the accumulation of photosynthetic products and the grain filling. The joint of controlled irrigation and SSNM improves the utilization efficiency of phosphorus.

\section{ACKNOWLEDGEMENTS}

This work was financially supported by Shandong Natural Science Foundation (NO. ZR2014EEQ020) and Shandong Water Conservancy Science and Technology Practice Project (NO. SDSLKY201502).

\section{REFERENCES}

[1]Shi R. H. 1989. Principles of Plant Nutrition. Jiangsu Science and Technology Publishing House: 293-295. (in Chinese) 
[2]Li Y. L. Cui Y. L. Lv G. A. Liang Z. C. Li Y. H. \& Feng Y. H. 2005. Phosphorus Efficiency and Water Productivity of Aerobic Rice under Different Water Regimes. Water Saving Irrigation (6): 15. (in Chinese)

[3]Fageria N. K. Barbosa M. P. Carvalho J. R. P. 1982. Response of upland rice to phosphorus fertilization on an oxisol of central Brazil. Agronomy Journal (74): 51-56.

[4]Lv G. A. Li Y. H. Sha Z. Y. Cao S. X. \& Liu X. C. 2000. Effect of Water-saving Irrigation on Phosphorus Nutrient in Rice. Irrigation and Drainage 19(4): 10-12. (in Chinese)

[5]Roy A. Wu Y. X. 2001. Phosphorus quantity-intensity relationships and agronomic measures of $P$ in surface layers of soil from a long-term slurry experiment. Chemosphere 42(2): 161-170.

[6]Zhou C. L. Yin J. L. \& Shen Q. R. 2002. Comparative study on the biomass, grain yield and phosphorus absorption of rice cultivated in waterlogged and aerobic conditions. Jiangsu Agricultural Sciences (5): 1-3. (in Chinese)

[7]Dobermann A. Witt C. \& Dawe D. 2002. Sit-specific nutrient management for intensities rice cropping systems in Asia. Field Crops Research (74): 37-66.

[8]Zhu W. Q. Wu L. H. Tao Q. N. 2004. Effects of water and nitrogen interaction on nitrogen from and some inorganic element content in the shoots of different rice varieties. Bulletin of Science and Technology 20(1): 1-5. (in Chinese)

[9]Peng S. Z. Hao S. R. Liu Q. Liu Y. \& Xu N. H. 2000. Study on the mechanisms of yield-raising and quality-improving for paddy rice under water-saving irrigation. Irrigation and Drainage 19(3): 3-7. (in Chinese) 